\title{
The Effects of 0.67 Hz High-pass Filtering on the Spatial QRS-T Angle
}

\author{
Daniel Guldenring ${ }^{1}$, Dewar D Finlay ${ }^{1}$, Raymond R Bond ${ }^{1}$, Alan Kennedy ${ }^{1}$, James McLaughlin ${ }^{1}$ \\ ${ }^{1}$ Ulster University, Belfast, United Kingdom
}

\begin{abstract}
The spatial QRS-T angle (SA) is a vectorcardiographic (VCG) parameter that has been identified as a marker for changes in the ventricular depolarization and repolarization sequence. Recent research has developed a number of different linear electrocardiographic lead transformation matrices that have removed the lead system related barriers for the utilization of the $S A$ in monitoring applications. However, monitoring applications utilize upon high-pass filters with cutoff frequencies as high as $0.67 \mathrm{~Hz}$. Such high-pass filters are known to influence the ST-segment of the electrocardiogram (ECG). The aim of this research was to quantify the influence of different $0.67 \mathrm{~Hz}$ high-pass monitoring filters on the SA. We assessed the differences between the $S A$ values computed from $0.05 \mathrm{~Hz}$ high-pass filtered Frank VCGs and $S A$ value obtained from different $0.67 \mathrm{~Hz}$ high-pass filtered VCGs $(0.67 \mathrm{~Hz}$ zero-phase high-pass filtered Frank VCGs, $0.67 \mathrm{~Hz}$ nonlinear-phase high-pass filtered Frank VCGs and $0.67 \mathrm{~Hz}$ zero-phase high-pass filtered VCGs derived from the Mason-Likar (ML) 12-lead ECG). The differences between the $S A$ values were determined using a study population of 181 subjects and quantified as random error (span of BlandAltman 95\% limits of agreement). The random error magnitude due to the derivation of the VCG from ML 12 lead ECG data was not found to be substantially increased by the utilization of the zero-phase $0.67 \mathrm{~Hz}$ high-pass filter (random error magnitude based upon $M L$ derived $0.67 \mathrm{~Hz}$ filtered VCG data: $45.40^{\circ}$ vs. random error magnitude based upon $M L$ derived $0.05 \mathrm{~Hz}$ filtered $V C G$ data $\left.39.57^{\circ}\right)$. This finding suggests that it is possible to utilize zero-phase (or alternatively linearphase) high-pass filters in SA monitoring applications that utilize VCG data derived from the ML 12-lead ECG.
\end{abstract}

\section{Introduction}

The spatial QRS-T angle (SA) is a vectorcardiographic parameter that can identify an abnormal relationship between ventricular depolarization and ventricular repolarization. It is known that repolarization and depolarization abnormalities are risk factors for the development ventricular arrhythmias [1]. Monitoring applications that allow for the recording of the SA are therefore of potential clinical interest. However, the SA has historically been obtained from Frank VCG data that has been recorded with the patient at rest. One reason for this was that the lead set of the Frank VCG is not compatible with monitoring applications. Recent research has developed a number of different linear electrocardiographic lead transformation matrices that have removed the lead system related barriers for the utilization of the SA in monitoring applications [2-4]. An example of such an electrocardiographic lead transformation matrix is the Guldenring matrix [2-4]. This matrix allows for the derivation of the SA from the monitoring compatible Mason-Likar (ML) 12-lead electrocardiogram (ECG) [5]. However, monitoring applications do not only require compatible electrocardiographic lead sets they also utilize upon different signal filter characteristics [6]. Higher levels of baseline wander are typically observed in monitoring ECGs when compared to resting ECGs. The reduction of the baseline wander in monitoring applications requires high-pass filters with cutoff frequencies that are higher than the cutoff frequencies that are used when recording resting ECGs. The American Heart Association states that monitoring ECGs can be recorded using high-pass filters with cutoff frequencies up to $0.67 \mathrm{~Hz}$ [7]. Monitoring high-pass filters are known to influence the ST-segment of the ECG. The effect of high-pass filters with a cutoff frequency of $0.67 \mathrm{~Hz}$ on the value of the SA has, to the best of our knowledge, not previously been reported in the literature. The aim of this research is to quantify the effect of high-pass filters with a $0.67 \mathrm{~Hz}$ cutoff frequency on the value of the SA.

\section{Material and methods}

\subsection{BSPM data}

We base our research on a study population of 229 normal subjects, 265 subjects with myocardial infarction and 232 subjects with left ventricular hypertrophy. One body surface potential map (BSPM) was recorded for each of the 726 subjects in the study population. Each BSPM used in this research contains electrocardiographic data of 120 BSPM leads. A representative average PQRST complex was calculated for each of the 120 BSPM leads. A comprehensive description of the BSPM data and the recording procedure can be found in [8] 


\subsection{Extraction of the Frank VCG data}

One Frank VCG was extracted from each of the 726 BSPMs. However, some of the body surface potentials that are used by the Frank VCG were associated with electrode locations that were not covered by the thoracic electrode grid. A previously reported two-step interpolation procedure [9] was used to obtain the required body surface potentials that were not directly recorded by the thoracic electrode grid. The body surface potentials at the A, C, E, F, H, I and M electrode locations of the Frank lead system were extracted from the interpolated BSPM data and subsequently used to derive the Frank VCG.

\subsection{Generation of the ML derived VCG data}

Limb leads I, II and precordial leads V1 to V6 of the ML 12-lead ECG were extracted from each BSPM in the study population. The extracted leads of the ML 12-lead ECGs were used to generate ML derived VCGs using (1).

$$
V C G_{M L}=A \cdot E C G_{M L}
$$

Where $\boldsymbol{E C G}_{\boldsymbol{M} \boldsymbol{L}}$ is a $8 \times N$ matrix that contains the $N$ sample values of limb leads I, II and precordial leads V1 to V6 of the ML 12-lead ECG, $\boldsymbol{A}$ refers to the Guldenring matrix [3,4] and $\boldsymbol{V} \boldsymbol{C} \boldsymbol{G}_{\boldsymbol{M L}}$ is a $3 \times N$ matrix containing $N$ sample values of the three ML derived Frank VCG.

\subsection{High-pass filtering of the VCG data}

Three different $0.67 \mathrm{~Hz}$ high-pass filtered VCGs and one $0.05 \mathrm{~Hz}$ high-pass filtered VCG were generated for each subject in the study population. This was achieved by applying different digital filters to the Frank VCGs and the ML derived VCGs. More precisely, one $0.67 \mathrm{~Hz}$ nonlinear-phase high-pass filtered VCG and one $0.67 \mathrm{~Hz}$ zero-phase high-pass filtered VCG were generated from each Frank VCG. In addition, one zero-phase high-pass filtered VCG was generated from each of the ML derived VCGs. A $1^{\text {st }}$ order Butterworth infinite impulse response (IIR) digital nonlinear-phase high-pass filter with a corner frequency located at $0.67 \mathrm{~Hz}$ was used to generated the nonlinear-phase high-pass filtered VCGs from the Frank VCGs. The zero-phase filtered VCGs were generated using a $1^{\text {st }}$ order IIR filter and forward-backward filtering [10]. The IIR filter that was used for forward-backward filtering of the VCGs was designed to have a signal attenuation of $1.5 \mathrm{~dB}$ at $0.67 \mathrm{~Hz}$. This ensured an overall attenuation of the signal (after both passes though the filter) of $3 \mathrm{~dB}$ at $0.67 \mathrm{~Hz}$. In addition, a $1^{\text {st }}$ order Butterworth IIR digital nonlinear-phase high-pass filter with a corner frequency located at $0.05 \mathrm{~Hz}$ was used to generate $0.05 \mathrm{~Hz}$ filtered VCGs from the Frank VCGs.

\subsection{Determination of the SA}

The SA values were calculated using the high-pass filtered VCGs as detailed in (2) to (6).

$$
\begin{aligned}
& \boldsymbol{Q} \boldsymbol{R} \boldsymbol{S}_{\boldsymbol{e}}^{\boldsymbol{d}}=\frac{1}{J_{p}-Q R S_{O N}} \sum_{n=Q R S_{O N}}^{J_{P}} \boldsymbol{V} \boldsymbol{C} \boldsymbol{G}_{\boldsymbol{e}}^{\boldsymbol{d}}(n) . \\
& \boldsymbol{T}_{\boldsymbol{e}}^{\boldsymbol{d}}=\frac{1}{T_{E N D^{-}-\left(J_{P}+1\right)}} \sum_{n=J_{P}+1}^{T_{E N D}} \boldsymbol{V} \boldsymbol{C} \boldsymbol{G}_{\boldsymbol{e}}^{\boldsymbol{d}}(n) . \\
& S A_{e}^{d}=\arccos \left[\frac{Q R S_{e}^{d} \cdot T_{e}^{d}}{\left|Q R S_{e}^{d}\right| \cdot\left|T_{e}^{d}\right|}\right] . \\
& S A Q R S_{e}^{f}=\arccos \left[\frac{\boldsymbol{Q R S _ { e } ^ { f }} \cdot \boldsymbol{T}_{\text {Frank }}^{\text {btw05 }}}{\left|\boldsymbol{Q R S _ { e } ^ { f }}\right| \cdot\left|\boldsymbol{T}_{\text {Frank }}^{\text {brw05 }}\right|}\right] .
\end{aligned}
$$

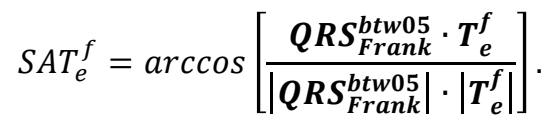

Where $\boldsymbol{Q} \boldsymbol{R} \boldsymbol{S}_{\boldsymbol{e}}^{\boldsymbol{d}}$ and $\boldsymbol{Q} \boldsymbol{R} \boldsymbol{S}_{\boldsymbol{e}}^{\boldsymbol{f}}$ are used to denote the $3 \times 1$ mean vector of the ventricular depolarization, $\boldsymbol{T}_{e}^{\boldsymbol{d}}$ and $\boldsymbol{T}_{\boldsymbol{e}}^{\boldsymbol{f}}$ are used to denote the $3 \times 1$ mean vector of ventricular repolarization, $\quad d \in\{z p 67, n l p 67$, btw 05$\}$ denotes whether a parameter was calculated from zero-phase 0.67 Hz high-pass filtered VCGs $(d=z p 67)$, nonlinear-phase $0.67 \mathrm{~Hz}$ high-pass filtered VCGs $(d=n l p 67)$ or Butterworth $0.05 \mathrm{~Hz}$ high-pass filtered VCGs $(d=$ btw05), $f \in\{z p 67, n l p 67\}$ denotes whether a parameter was calculated from zero-phase $0.67 \mathrm{~Hz}$ high-pass filtered VCGs $(f=z p 67)$ or nonlinear-phase $0.67 \mathrm{~Hz}$ high-pass filtered VCGs $(f=n l p 67), e \in\{$ Frank, $M L\}$ denotes whether a parameter was calculated from the Frank VCG $(e=$ Frank $)$ or the ML derived VCG $(e=M L)$, $S A Q R S_{e}^{f}$ and $S A T_{e}^{f}$ denote composite SA values.

\subsection{Quantification of the effect of $0.67 \mathrm{~Hz}$ high-pass filtering on the SA}

The effect of the two different $0.67 \mathrm{~Hz}$ high-pass filters on the value of the SA was quantified. This was performed using a multistep procedure. First, the differences between the SA values based upon $0.67 \mathrm{~Hz}$ high-pass filtered VCG data and the SA values based upon $0.05 \mathrm{~Hz}$ high-pass filtered Frank VCG data were calculated as detailed in (7).

$$
\Delta S A_{e}^{f}=S A_{e}^{f}-S A_{\text {Frank }}^{b t w 05} .
$$

Where $\boldsymbol{S} \boldsymbol{A}_{\boldsymbol{e}}^{\boldsymbol{f}}$ is a vector that contains the SA values of all subjects in the study population based upon $0.67 \mathrm{~Hz}$ high-pass filtered VCG data, $\boldsymbol{S} \boldsymbol{A}_{\text {Frank }}^{\boldsymbol{b t w 0 5}}$ is a vector that contains the SA values of all subjects in the study population based upon Butterworth $0.05 \mathrm{~Hz}$ high-pass filtered Frank VCG data, $\Delta \boldsymbol{S} \boldsymbol{A}_{\boldsymbol{e}}^{f}$ is a vector that contains the differences between the SA values based upon 0.67 
$\mathrm{Hz}$ and $0.05 \mathrm{~Hz}$ high-pass filtered VCG data, $e$ and $f$ are as defined for (2) to (6).

Second, the systematic and the random error component of the differences between the SA values that are based upon $0.67 \mathrm{~Hz}$ and $0.05 \mathrm{~Hz}$ high-pass filtered VCG data were analyzed. The mean of the different $\Delta S A_{e}^{f}$ vectors was used to quantify the systematic error. We quantified the random error using the span of the Bland-Altman 95\% limits of agreement as detailed in (8).

$$
R E_{e}^{f}=2 \cdot 1.96 \cdot \operatorname{std}\left(\Delta \boldsymbol{S} \boldsymbol{A}_{\boldsymbol{e}}^{f}\right) .
$$

Where $\operatorname{std}(\cdot)$ denotes the standard deviation and $\Delta \boldsymbol{S} \boldsymbol{A}_{\boldsymbol{e}}^{\boldsymbol{f}}$ is as defined in (7).

Third, we assessed the contribution of the changes (due to the $0.67 \mathrm{~Hz}$ high-pass filter and for $e=M L$ also due to the derivation of the VCG from the ML 12-lead ECG) in the mean QRS-vector and the mean T-vector to the $\Delta S A_{e}^{f}$ values. This was performed through the use of the linear model in (9).

$$
\begin{gathered}
\widehat{\Delta S A_{e}^{f}}=b_{1} \cdot \Delta S A Q R S_{e}^{f}+b_{2} \cdot \Delta S A T_{e}^{f} . \\
\Delta S A Q R S_{e}^{f}=\left(S A Q R S_{e}^{f}-S A_{\text {Frank }}^{\text {btw05 }}\right) . \\
\Delta S A T_{e}^{f}=\left(S A T_{e}^{f}-S A_{\text {Frank }}^{\text {btw05 }}\right) .
\end{gathered}
$$

Where $b_{1}$ and $b_{2}$ are the coefficients of the linear model, $S A_{\text {Frank }}^{b t w 05}$ denotes the SA value of one subject in the study population based upon Butterworth $0.05 \mathrm{~Hz}$ high-pass filtered Frank VCG data, $S A Q R S_{e}^{f}$ and $S A T_{e}^{f}$ are as defined in (5) and (6) respectively, $\widehat{\Delta S A_{e}^{f}}$ denotes the estimate of the $\Delta S A_{e}^{f}$ value associated with one subject in the study population, $\triangle S A Q R S_{e}^{f}$ denotes the contribution of the changes in the mean QRS-vector to the $\Delta S A_{e}^{f}$ value and $\triangle S A T^{e}$ denotes the contribution of changes in the mean T-vector to the $\Delta S A_{e}^{f}$ value, $e$ and $f$ are as defined for (2) to (6).

Random sampling was used to divide the study population into a training dataset (DTrain) and a testing dataset (DTest). The coefficients in (9) were developed using the VCG data of the 545 subjects in DTrain and linear least squares regression. The performance of the linear model in (9) was assessed using the VCG data of the 181 subjects in DTest. The performance of the linear model in (9) was quantified using the Root-Mean-SquareDifference (RMSD) between the $\widehat{\Delta S A_{e}^{f}}$ and the $\Delta S A_{e}^{f}$ values of all subjects in DTest. The scale of the predictor variables was quantified using the mean absolute magnitude (MAD) of the predictor variables $\triangle S A Q R S_{e}^{f}$ and $\triangle S A T_{e}^{f}$ of the linear model in (9).

\section{Results}

Table 1. Differences between the SA values obtained

\begin{tabular}{|c|c|c|}
\hline Parameter & $\begin{array}{l}\text { Parameter } \\
\text { value }\end{array}$ & $\begin{array}{c}95 \% \text { Confidence } \\
\text { Interval }\end{array}$ \\
\hline Random error magnitude & $31.74^{\circ}$ & {$\left[25.50^{\circ}\right.$ to $\left.37.57^{\circ}\right]$} \\
\hline Systematic error & $-5.54^{\circ}$ & {$\left[-6.73^{\circ}\right.$ to $\left.-4.36^{\circ}\right]$} \\
\hline${ }^{\mathrm{a}} b_{1}$ & 0.97 & [0.96 to 0.98$]$ \\
\hline$b_{2}$ & 1.00 & {$[1.00$ to 1.00$]$} \\
\hline${ }^{\mathrm{b}} R M S D$ & $0.12^{\circ}$ & {$\left[0.07^{\circ}\right.$ to $\left.0.16^{\circ}\right]$} \\
\hline$\left|\Delta S A Q R S_{\text {Frank }}^{\text {zp67 }}\right|$ & $0.81^{\circ}$ & {$\left[0.66^{\circ}\right.$ to $\left.1.00^{\circ}\right]$} \\
\hline$\overline{\left|\Delta S A T_{\text {Frank }}^{\text {zp67 }}\right|}$ & $6.79^{\circ}$ & {$\left[5.80^{\circ}\right.$ to $\left.7.89^{\circ}\right]$} \\
\hline
\end{tabular}
from $0.05 \mathrm{~Hz}$ high-pass filtered Frank VCG data and the SA values obtained from zero-phase $0.67 \mathrm{~Hz}$ high-pass filtered Frank VCG data.

${ }^{\text {a Regression coefficients of the model in (9) for } f=z p 67 \text { and }}$ $e=$ Frank,${ }^{\mathrm{b}} \mathrm{RMSD}$ between the $\Delta S \overline{A_{\text {Frank }}^{\text {Zp67 }}}$ and the $\Delta S A_{\text {Frank }}^{\text {Zp67 }}$

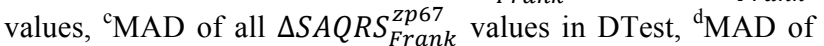
all $\triangle S A T_{\text {Frank }}^{Z p 67}$ values in DTest.

Table 2. Differences between the SA values obtained

\begin{tabular}{|c|c|c|}
\hline Parameter & $\begin{array}{l}\text { Parameter } \\
\text { value }\end{array}$ & $\begin{array}{l}\text { 95\% Confidence } \\
\text { Interval }\end{array}$ \\
\hline Random error magnitude & $77.66^{\circ}$ & {$\left[61.68^{\circ}\right.$ to $\left.94.31^{\circ}\right]$} \\
\hline Systematic error & $26.36^{\circ}$ & [23.46 to $\left.29.27^{\circ}\right]$ \\
\hline$b_{1}$ & 0.89 & [0.86 to 0.91$]$ \\
\hline$b_{2}$ & 1.00 & [1.00 to 1.00$]$ \\
\hline bMSD & $0.72^{\circ}$ & {$\left[0.42^{\circ}\right.$ to $\left.1.04^{\circ}\right]$} \\
\hline$\overline{\left|\Delta S A Q R S_{\text {Frank }}^{\text {nlp67 }}\right|}$ & $2.30^{\circ}$ & {$\left[1.98^{\circ}\right.$ to $\left.2.71^{\circ}\right]$} \\
\hline $\mathrm{d}\left|\Delta S A T_{\text {Frank }}^{\text {nlp67 }}\right|$ & $25.45^{\circ}$ & {$\left[22.72^{\circ}\right.$ to $\left.28.40^{\circ}\right]$} \\
\hline \multicolumn{3}{|c|}{ 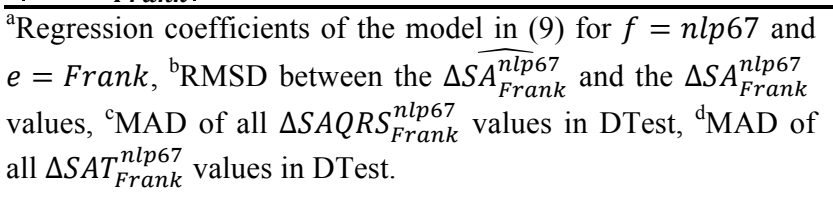 } \\
\hline
\end{tabular}
from $0.05 \mathrm{~Hz}$ high-pass filtered Frank VCGs and the SA values obtained from nonlinear-phase $0.67 \mathrm{~Hz}$ high-pass filtered Frank VCGs.

Table 3. Differences between the SA values obtained from $0.05 \mathrm{~Hz}$ high-pass filtered Frank VCGs and the SA values obtained from zero-phase $0.67 \mathrm{~Hz}$ high-pass filtered VCGs that were derived from ML 12-lead ECG data.

\begin{tabular}{lcc}
\hline \multicolumn{1}{c}{ Parameter } & $\begin{array}{c}\text { Parameter } \\
\text { value }\end{array}$ & $\begin{array}{c}95 \% \text { Confidence } \\
\text { Interval }\end{array}$ \\
\hline Random error magnitude & $45.40^{\circ}$ & {$\left[38.95^{\circ}\right.$ to $\left.51.44^{\circ}\right]$} \\
\hline Systematic error & $-2.67^{\circ}$ & {$\left[-4.37^{\circ}\right.$ to $\left.-0.97^{\circ}\right]$} \\
\hline${ }^{\mathrm{a}} b_{1}$ & 1.04 & {$[0.93$ to 1.15$]$} \\
\hline
\end{tabular}




\begin{tabular}{|c|c|c|}
\hline$b_{2}$ & 0.73 & [0.64 to 0.81$]$ \\
\hline${ }^{\mathrm{b}} R M S D$ & $11.94^{\circ}$ & {$\left[8.49^{\circ}\right.$ to $\left.15.71^{\circ}\right]$} \\
\hline$\left|\triangle S A Q R S_{M L}^{z p 67}\right|$ & $4.86^{\circ}$ & {$\left[4.24^{\circ}\right.$ to $\left.5.40^{\circ}\right]$} \\
\hline $\mid \overline{\Delta S A T_{M L}^{z p 67} \mid}$ & $7.63^{\circ}$ & {$\left[6.62^{\circ}\right.$ to $\left.8.78^{\circ}\right]$} \\
\hline \multicolumn{3}{|c|}{$\begin{array}{l}{ }^{\mathrm{a}} \text { Regression coefficients of the model in (9) for } f=z p 67 \text { and } \\
e=M L \text {, }{ }^{\mathrm{b}} \mathrm{RMSD} \text { between the } \triangle S A_{M L}^{z p 67} \text { and the } \triangle S A_{M L}^{z p 67} \text { values, } \\
e={ }^{\mathrm{c}} \mathrm{MAD} \text { of all } \triangle S A Q R S_{M L}^{z 267} \text { values in DTest, }{ }^{\mathrm{d}} \mathrm{MAD} \text { of all } \\
\Delta S A T_{M L}^{Z p 67} \text { values in DTest. }\end{array}$} \\
\hline
\end{tabular}

\section{Discussion}

The random error components that are introduced through the utilization of the $0.67 \mathrm{~Hz}$ zero-phase highpass filter and the $0.67 \mathrm{~Hz}$ nonlinear-phase high-pass filter were found to be $31.74^{\circ}$ and $77.66^{\circ}$ respectively. These findings indicate that the utilization of zero-phase (or alternatively linear-phase) filters is associated with a notable lower random error component when compared to what is achieved by the nonlinear-phase $0.67 \mathrm{~Hz}$ highpass filter. The coefficients $\left(b_{1}=0.97, b_{2}=1.00\right)$ of the linear model in (9) and the scale of the predictor variables

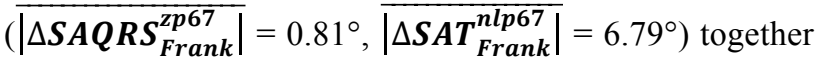
with the low RMSD value of $0.12^{\circ}$ identify the changes in the mean vector of the ventricular depolarization as the main contributor to the random error in the SA values that are obtained from zero-phase $0.67 \mathrm{~Hz}$ high-pass filtered Frank VCG data. Derived VCGs, that are obtained using monitoring compatible reduced lead systems, are used in SA monitoring applications. The random error component that is observed in SA monitoring applications therefore includes the errors due to the derivation of the VCG from monitoring compatible lead sets and the error due to 0.67 $\mathrm{Hz}$ high-pass filtering. The random error component due the combined effect of the derivation of the VCG from the ML 12-lead ECG and the $0.67 \mathrm{~Hz}$ zero-phase highpass filter was found to be $45.40^{\circ}$ [95\% confidence interval: $38.95^{\circ}$ to $51.44^{\circ}$ ]. This random error magnitude is similar to the random error magnitudes of $39.57^{\circ}$ (based on ML derived VCG data) [4] and $55^{\circ}$ (based on VCG data derived from the standard 12-lead ECG) [11] that have previously been reported when the SA was derived without the use of a $0.67 \mathrm{~Hz}$ high-pass filter.

\section{Conclusion}

Zero-phase or, alternatively, linear-phase $0.67 \mathrm{~Hz}$ high-pass filters should be preferred over non-linear phase $0.67 \mathrm{~Hz}$ high-pass filters when recording the SA in monitoring applications. The utilization of zero-phase $0.67 \mathrm{~Hz}$ high-pass filters in SA monitoring application was found to not substantially decrease the quality of SA values that are derived from the ML 12-lead ECG.

\section{Acknowledgements}

This work has been supported by the CHESS project funded by the European Commission under the Horizon 2020 Programme (Grant no. 676201).

\section{References}

[1] Peeters HA, Sippensgroenewegen A, Wever EF, Potse M, Daniels $\mathrm{MC}$, Grimbergen $\mathrm{CA}$, et at. Electrocardiographic identification of abnormal ventricular depolarization and repolarization in patients with idiopathic ventricular fibrillation. J. Am. Coll. Cardiol. 1998; 31(6):1406-1413.

[2] Guldenring D, Finlay DD, Strauss DG, Galeotti L, Nugent CD, Donnelly MP, et al. Reconstruction of the Frank vectorcardiogram from standard electrocardiographic leads: diagnostic comparison of different methods. Conf Proc IEEE Eng Med Biol Soc 2012; (34): 677-680.

[3] Guldenring D, Finlay DD, Bond RR, Kennedy A, McLaughlin J, Galeotti L, et al. The derivation of the spatial QRS-T angle and the spatial ventricular gradient using the Mason-Likar 12-lead electrocardiogram. J Electrocardiol 2015; 48(6):1045-1052.

[4] Guldenring D, Finlay D, Bond R, Kennedy A, McLaughlin J, Galeotti L, et al. Computing the Spatial QRS-T Angle Using Reduced Electrocardiographic Lead Sets. J Electrocardiol 2016; 49(6):794-799.

[5] Mason RE, Likar I. A new system of multiple-lead exercise electrocardiography. Am. Heart J. 1966; 71(2): 196-205.

[6] Guldenring D, Finlay D, Bond R, Kennedy A, McLaughlin J, Moran K. The Effects of $40 \mathrm{~Hz}$ Low-pass Filtering on the Spatial QRS-T Angle. Computing in Cardiology 2016;43:93-96.

[7] Kligfield P, Gettes LS, Bailey JJ, Childers R, Deal BJ, Hancock EW, et al. Recommendations for the Standardization and Interpretation of the Electrocardiogram: Part I: The Electrocardiogram and Its Technology. Circulation 2007; 115(10):1306-1324.

[8] Montague TJ, Smith ER, Cameron DA, Rautaharju PM, Klassen GA, Felmington CS, et al. Isointegral analysis of body surface maps: surface distribution and temporal variability in normal subjects. Circulation 1981; 63(5): 1166-1172.

[9] Finlay DD, Nugent CD, Nelwan SP, Bond RR, Donnelly MP, Guldenring D. Effects of electrode placement errors in the EASI-derived 12-lead electrocardiogram. J Electrocardiol 2010; 43(6): 606-611.

[10] Gustafsson F. Determining the Initial States in ForwardBackward Filtering. IEEE Trans Signal Process 1996; 44(4):988-992.

[11] Schreurs C, Algra A, Man S, Cannegieter S, van der Wall E, Schalij M, et al. The spatial QRS-T angle in the Frank vectorcardiogram: accuracy of estimates derived from the 12lead electrocardiogram. J Electrocardiol 2010;43(4):294-301.

Address for correspondence.

Daniel Guldenring

Room 25B05, School of Engineering, Ulster University,

Shore Road, Newtownabbey, Co. Antrim, BT37 0QB

guldenring-d2@email.ulster.ac.uk 